\title{
Article \\ Identification of the Capsicum baccatum NLR Protein CbAR9 Conferring Disease Resistance to Anthracnose
}

\author{
Seungmin Son ${ }^{1}{ }^{1}$, Soohong Kim ${ }^{1}$, Kyong Sil Lee ${ }^{1}$, Jun Oh ${ }^{1}$, Inchan Choi ${ }^{1}$, Jae Wahng Do ${ }^{2}$, Jae Bok Yoon ${ }^{2}$, \\ Jungheon Han ${ }^{1}$, Doil Choi ${ }^{3}$ and Sang Ryeol Park ${ }^{1, * \mathbb{D}}$ \\ 1 National Institute of Agricultural Sciences, Rural Development Administration, Jeonju 54874, Korea; \\ linewind@korea.kr (S.S.); island1984@naver.com (S.K.); golderic@naver.com (K.S.L.); \\ osculation@korea.kr (J.O.); inchchoi@korea.kr (I.C.); jungheon1@hanmail.net (J.H.) \\ 2 Pepper and Breeding Institute, K-Seed Valley, Gimje 54324, Korea; wahng0@hanmail.net (J.W.D.); \\ jaebokyoon@hanmail.net (J.B.Y.) \\ 3 Plant Genomics and Breeding Institute, Research Institute for Agriculture and Life Sciences, Seoul National \\ University, Seoul 08826, Korea; doil@snu.ac.kr \\ * Correspondence: srpark@korea.kr; Tel.: +82-63-238-4582
}

check for updates

Citation: Son, S.; Kim, S.; Lee, K.S.; Oh, J.; Choi, I.; Do, J.W.; Yoon, J.B.;

Han, J.; Choi, D.; Park, S.R.

Identification of the Capsicum baccatum NLR Protein CbAR9 Conferring Disease Resistance to Anthracnose. Int. J. Mol. Sci. 2021, 22, 12612. https://doi.org/10.3390/ ijms222212612

Academic Editor: Maria R. Ercolano

Received: 20 October 2021

Accepted: 18 November 2021

Published: 22 November 2021

Publisher's Note: MDPI stays neutral with regard to jurisdictional claims in published maps and institutional affiliations.

Copyright: (C) 2021 by the authors. Licensee MDPI, Basel, Switzerland. This article is an open access article distributed under the terms and conditions of the Creative Commons Attribution (CC BY) license (https:/ / creativecommons.org/licenses/by/ $4.0 /)$.

\begin{abstract}
Anthracnose is caused by Colletotrichum species and is one of the most virulent fungal diseases affecting chili pepper (Capsicum) yield globally. However, the noble genes conferring resistance to Colletotrichum species remain largely elusive. In this study, we identified CbAR9 as the causal locus underlying the large effect quantitative trait locus $C c R 9$ from the anthracnose-resistant chili pepper variety PBC80. CbAR9 encodes a nucleotide-binding and leucine-rich repeat (NLR) protein related to defense-associated NLRs in several other plant species. CbAR9 transcript levels were induced dramatically after Colletotrichum capsici infection. To explore the biological function, we generated transgenic Nicotiana benthamiana lines overexpressing CbAR9, which showed enhanced resistance to $C$. capsici relative to wild-type plants. Transcript levels of pathogenesis-related $(P R)$ genes increased markedly in CbAR9-overexpressing N. benthamiana plants. Moreover, resistance to anthracnose and transcript levels of $P R 1$ and $P R 2$ were markedly reduced in CbAR9-silenced chili pepper fruits after $C$. capsici infection. Our results revealed that CbAR9 contributes to innate immunity against $C$. capsici.
\end{abstract}

Keywords: Capsicum baccatum; Colletotrichum capsici; innate immunity; Nicotiana benthamiana; nucleotidebinding and leucine-rich repeat

\section{Introduction}

Chili pepper (Capsicum) is an economically important crop providing food, spices, and medicinals [1-3]. Pepper is a member of the Solanaceae family, which also includes potato (Solanum tuberosum), tomato (Solanum lycopersicum), tobacco (Nicotiana sp.), and petunia (Petunia $\times$ atkinsiana) [4]. Members of the Solanaceae have similar numbers of chromosomes $(n=12)$, although their genome sizes can vary largely [5]. Indeed, the genomes of pepper species are typically larger, being about four times that of tomato, due to a greater fraction of repetitive sequences [6]. Of the approximately 40 species in the Capsicum genus [7], the only domesticated ones are bell pepper (C. annuum), cayenne pepper (C. frutescens), habanero pepper (C. chinense), locoto pepper (C. baccatum), and rocoto pepper (C. pubescens) [8]. Of those, C. chinense and C. baccatum harbor valuable genes for plant breeding [9]. In 1998, the World Vegetable Center identified three anthracnoseresistant varieties in these species-C. chinense variety 'PBC932' and C. baccatum varieties 'PBC80' and 'PBC81' [10] - paving the way for botanists to introduce anthracnose resistance into other varieties using conventional breeding and embryo rescue [11]. In particular, the C. baccatum resistant variety PBC80 showed broad-spectrum resistance (BSR), conferring resistance to at least two pathogenic species or to the majority of races/strains of the 
same pathogen [12], as well as to the three main Colletotrichum species causing pepper anthracnose: C. acutatum, C. capsici, and C. gloeosporioides [13-15]. The resistance genes originating from variety $\mathrm{PBC} 80$ have therefore been the focus of much attention toward their identification and characterization.

Plants and animals alike use nucleotide-binding and leucine-rich repeat (NLR) proteins to respond to invading pathogens through the activation of innate immunity [16-18]. The NLR family is one of the most variable gene families in plant genomes [19], and plant NLRs play various roles such as sensors, helpers, and executors in response to pathogen infection [20]. Plant NLRs are divided into three main groups based on the accompanying functional domains at their $\mathrm{N}$ termini: Toll/interleukin-1 receptor (TIR) domain, coiled-coil (CC) domain, and resistance to powdery mildew 8 (RPW8)-type CC $\left(C_{R}\right)$ domain [21]. Plant NLRs also contain a central nucleotide-binding site (NBS) and C-terminal leucine-rich repeats (LRRs) [22].

Plants possess two major innate immunity systems: pathogen-associated molecular pattern (PAMP)-triggered immunity (PTI) and effector-triggered immunity (ETI) [23]. PTI signaling is initiated by the recognition of PAMPs by pattern recognition receptors (PRRs) residing in the plasma membrane, and it results in transcriptional reprograming and generation of defense components that increase resistance to a wide range of pathogens [24]. To overcome this defense mechanism, pathogens produce effectors required for inhibition of PTI and activation of effector-triggered susceptibility (ETS) [25]. Counteracting pathogen effector strategy, plants activate ETI through perception of effectors by NLRs, a wellcharacterized representative intracellular resistance $(R)$ protein that recognizes specific pathogen effectors [26-28]. NLR-mediated ETI leads to a hypersensitive response (HR), which is characterized by a burst of reactive oxygen species and programmed cell death associated with disease resistance at the infected site [29-31]. HR also induces a secondary resistance response known as systemic acquired resistance (SAR), which confers longlasting protection against a broad spectrum of pathogens throughout the infected plant [32].

Some of the sensor NLR (sNLR) receptors, such as RRS1 and RGA5, contain an integrated decoy domain that binds directly to effector [33]. However, since most characterized plant NLRs contain no integrated decoy domain [34], sNLR receptors have been proposed to interact with effectors indirectly through either an accessory protein, as in the guard model hypothesis, or via a structural mimic as in the decoy model [35-37]. Moreover, a subset of activated sNLRs also requires a helper NLR (hNLR) to transduce the ETI signal to downstream signaling components, with hNLRs in fact having been recently proposed to act as signaling hubs for a diverse array of sNLRs $[33,38,39]$. However, the noble NLR genes conferring resistance to Colletotrichum species remain largely elusive.

Pepper production is currently under threat by anthracnose disease, which is caused by Colletotrichum species and can result in losses of up to $80 \%$ of the harvest [40]. Therefore, identifying genes conferring resistance to Colletotrichum species is a high-priority goal for pepper breeding. Previous genomic studies showed that the NLR gene family is highly expanded and diversified in chili pepper [6,41]. Moreover, we previously mapped quantitative trait loci (QTLs) for resistance against C. capsici on chromosome 9, and for resistance to C. acutatum on chromosome 12, using composite interval mapping (CIM) [42]. Recently, we identified $\mathrm{CbCN}$ conferring resistance to C. acutatum from QTL located on chromosome 12 [43]. However, the noble genes involved in innate immunity against $C$. capsici remain to elucidated.

We previously showed that the major $C c R 9$ QTL for resistance against $C$. capsici maps between the markers HpmsE143 and EtgaMccg10 on chromosome 9; CcR9 alone explained $>50 \%$ of the standing phenotypic variance for several anthracnose resistance-associated parameters [42]. Since NLR proteins play critical roles in innate immunity, here, we identified the NLR gene CbAR9 from PBC80 as responsible for the QTL on chromosome 9. Molecular and genetic studies revealed that $C b A R 9$ confers resistance to $C$. capsici in chili pepper. 


\section{Results}

2.1. CbAR9 Encoding a Typical NLR Protein Is Identified from the CcR9 QTL of C. baccatum PBC 80

To identify candidate genes associated with anthracnose resistance, we analyzed the $C c R 9$ mapping interval in the C. baccatum genome and identified the expressed NLR genes (Figure 1A). The four genes such as CB.CBv1.2.scaffold1468.5/1022.13/778.14/778.16 encode a typical NLR protein, while the seven genes such as CB.CBv1.2.scaffold1022.20/2141.4/778.4/778.11/778.13/778.21/778.26 encoded an atypical NLR proteins (Figure 1B). To know genetic divergence, we performed phylogenic analysis based on amino acid sequence of the candidate genes (Table S1). As a result, phylogenic tree showed that CbAR9 (CB.CBv1.2.scaffold1468.5) is remarkable different to the other candidate proteins (Figure S1).

A

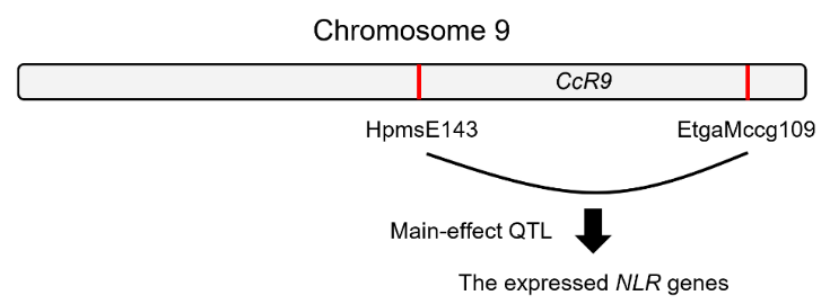

B

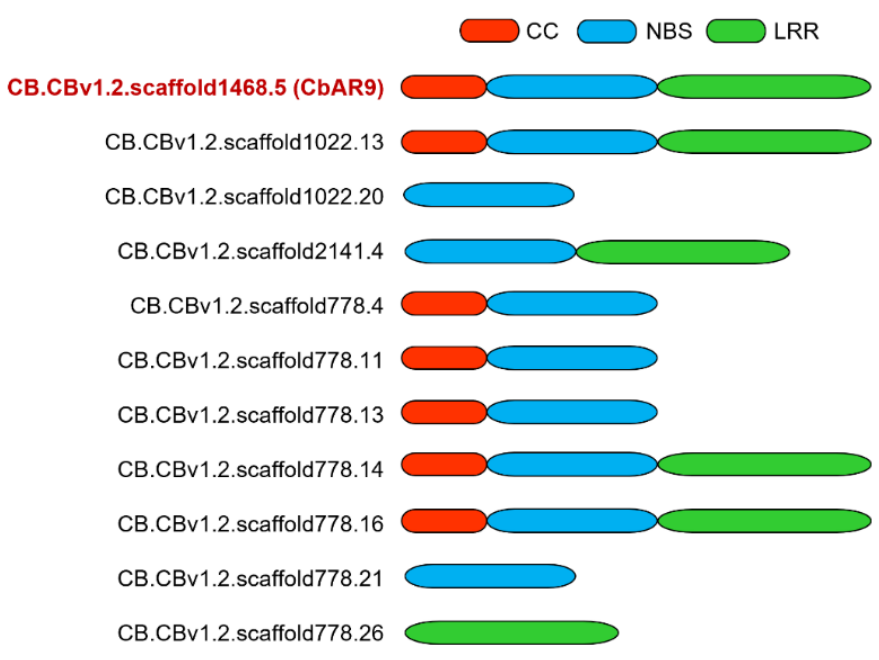

Figure 1. NLR-encoding candidate genes identified from the main-effector QTL of Capsicum baccatum resistant variety PBC80. (A) Schematic diagram of the identification of CbAR9 as the main-effect QTL CcR9 on chromosome 9 of the C. baccatum resistant variety PBC80. (B) Schematic representation of the identified candidate NLR proteins identified from the main-effector QTL of C. baccatum resistant variety PBC80. Red, CC domain; blue, NBS domain; green, LRR domain.

\subsection{CbAR9 Is Highly Conserved in Other Pepper Species, and the Transcription Level of It Is Dramatically Upregulated by C. capsici}

CbAR9 encoded a typical CC-type NLR protein in the chili pepper resistant variety PBC80 (Figure 2A). The cDNA sequence of CbAR9 consisted of $2748 \mathrm{bp}$ and encoded a protein of 915 amino acids with a predicted molecular weight of $104.3 \mathrm{kDa}$ and an isoelectric point of 7.06. An analysis of conserved domains with InterPro and other classification software tools revealed a CC domain from amino acids 2 to 125, an NBS domain from amino acids 166 to 401, and a LRR domain from amino acids 547 to 869 (Figure 2A). Using CbAR9 as a query, we identified two NLR proteins: one in bell pepper (CaNLR, XP_016566298) and one in habanero pepper (CcNLR, PHU21239) that were over 98\% identical to CbAR9 
(Figure 2A). In addition, we searched for NLR proteins with the same domain arrangement as CbAR9 in other plant species using SmartBLAST, yielding NLR proteins from soybean (Glycine max) and Arabidopsis (Arabidopsis thaliana) that are highly similar with CbAR9 over the length of the NLR domains (Figure S2). Phylogenic analysis indicated that CbAR9 clusters with other pepper NLR proteins, followed by Solanaceae proteins, which will be informative for pepper breeding using CbAR9 based on sequence similarity (Figure 2B).

A

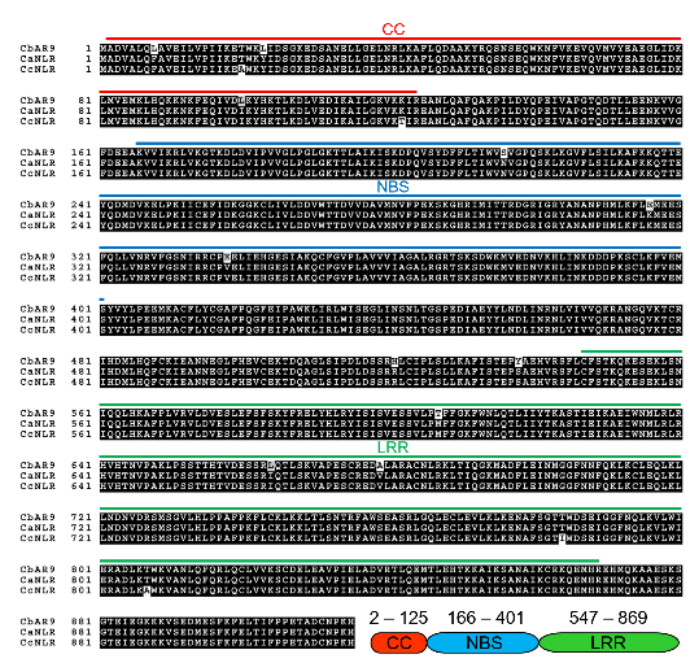

B
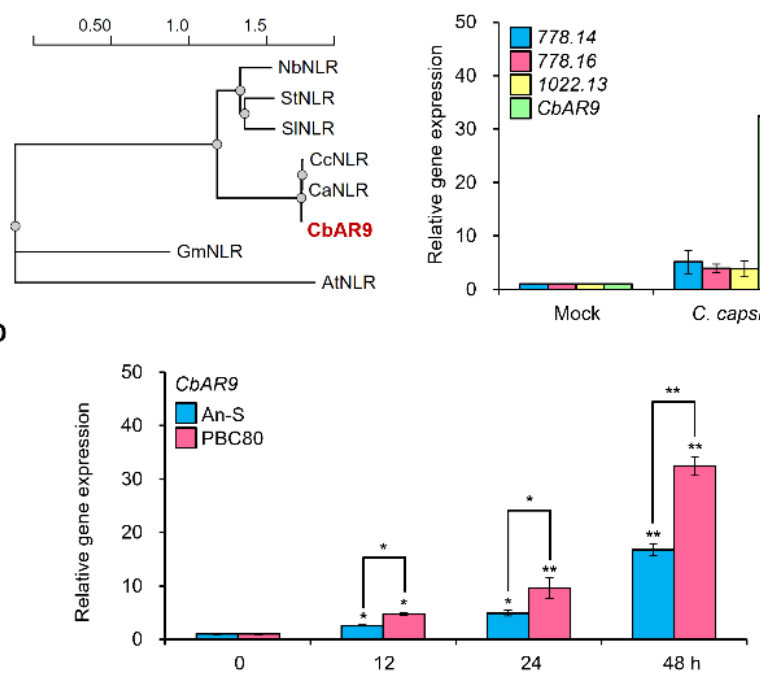

Figure 2. CbAR9 encodes a highly conserved NLR protein, and its expression is induced by Colletotrichum capsici infection. (A) Multiple protein sequence alignment between CbAR9 and two homologous NLR proteins from Capsicum annuum (XP_016566298) and Capsicum chinense (PHU21239). Red, CC domain; blue, NBS domain; green, LRR domain. (B) Phylogenetic analysis of CbAR9. A neighbor-joining tree was constructed with NGPhylogeny software using the full-length protein sequence of CbAR9, CaNLR (XP_016566298), CcNLR (PHU21239), NbNLR (QER78241), SINLR (XP_010319428), StNLR (XP_015161267), GmNLR (XP_006601748), and AtNLR (NP_001332515). The scale bar represents the proportion of site changes along each branch. (C) Relative transcription levels of CB.CBv1.2.scaffold778.14/778.16/1022.13 and CbAR9 in PBC80 after C. capsici inoculation for $48 \mathrm{~h}$, as determined by RT-qPCR. Actin served as internal reference. Data are shown as means \pm SD. Asterisks indicate statistically significant differences from controls ( $\left.{ }^{* *} p<0.01\right)$. (D) Relative CbAR9 transcript levels in An-S and PBC80 after C. capsici infection for the indicated times, as determined by RT-qPCR. Actin served as the internal reference. Data are shown as means \pm SDs. Asterisks indicate statistically significant differences from controls $\left({ }^{*} p<0.05\right.$ and $\left.{ }^{* *} p<0.01\right)$. The experiments were repeated at least three times, with similar results.

Since NLR genes related to innate immunity are commonly induced by pathogen infection [44], we measured transcription levels of the four candidate genes encoding a typical NLR in response to anthracnose disease by infecting plants with C. capsici. Indeed, $C b A R 9$ expression was dramatically induced in PBC $8048 \mathrm{~h}$ after C. capsici inoculation. In order to monitor the expression pattern of $C b A R 9$ in detail, the chili pepper variety An-S and $\mathrm{PBC} 80$ were inoculated with C. capsici. CbAR9 transcript levels rose to higher levels in the resistant variety $\mathrm{PBC} 80$ than in the susceptible variety An-S by C. capsici. (Figure 2D). Therefore, we focused primarily on $C b A R 9$ among the candidate genes.

\subsection{Overexpression of CbAR9 Enhances Resistance to C. capsici Infection}

To elucidate the biological function of CbAR9 in plants, we generated transgenic Nicotiana benthamiana plants constitutively expressing CbAR9 $\left(C b A R 9^{O X}\right)$. We validated the presence and expression of the transgene by RT-qPCR analysis (Figure S3A). Since activation of innate immunity system effects plant growth and development, overexpression of immune genes frequently causes a constitutive immunity phenotype. However, $\mathrm{CbAR9}{ }^{\mathrm{OX}}$ did not show any visible growth phenotypes (Figure S3B). When we examined whether $\mathrm{CbAR} 9$ modulates disease resistance to anthracnose, surprisingly, $\mathrm{CbAR9}{ }^{\mathrm{OX}}$ plants 
exhibited strong resistance to anthracnose caused by $C$. capsici compared with the wild-type plant (Figure 3A). Quantitative analysis also showed $C b A R 9^{\circ}$ plants developed smaller lesions compared to wild-type plants after C. capsici infection (Figure 3B). To monitor the expression of innate immunity-related genes, we performed RT-qPCR 6 days after $C$. capsici infection in wild-type and $C b A R 9^{O X}$ plants. We observed strong induction (20- to 50-fold relative to the wild type) of the expression of $P R$ genes such as NbPR1, NbPR2, and NbPR10 in $C b A R 9^{O X}$ (Figure $3 C$ ). However, expression levels of them did not change dramatically in $\mathrm{CbAR9}{ }^{\mathrm{OX}}$ compared with wild-type plant after mock treatment (Figure $3 \mathrm{C}$ ).

A



C

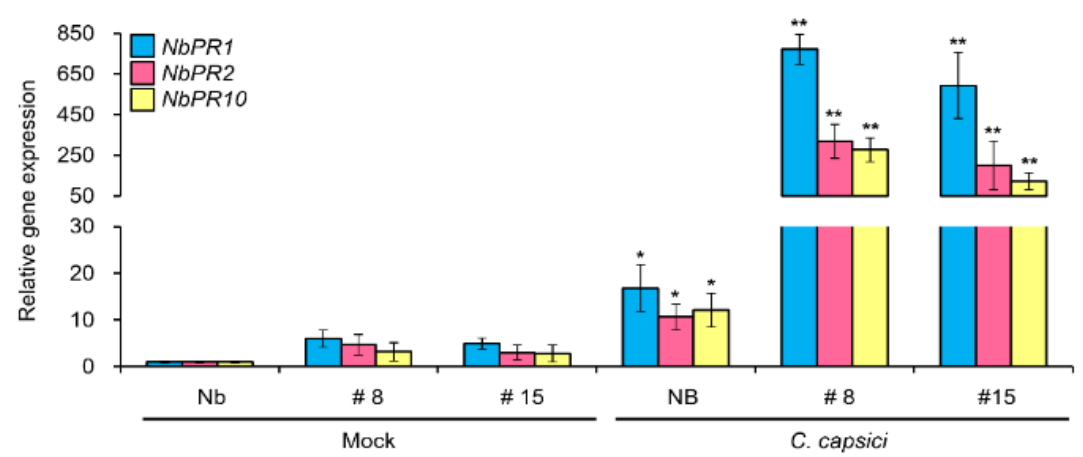

B

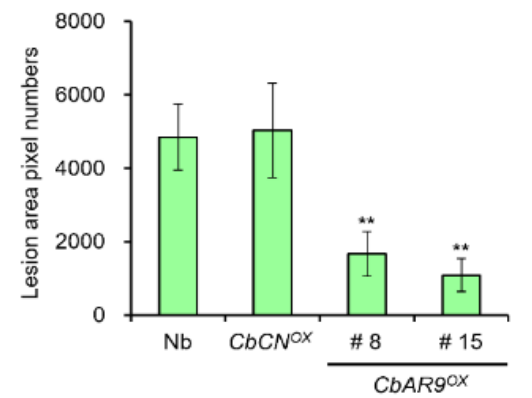

Figure 3. Overexpression of $C b A R 9$ enhances resistance to anthracnose disease caused by Colletotrichum capsici infection. (A,B) Anthracnose disease resistance assays of CbAR9OX Nicotiana benthamiana plants. 4-week-old $\mathrm{CbAR9} O \mathrm{X}$ and wild-type plants were inoculated with C. capsici. Images were captured after 6 days (A), and the progression of the disease was quantified using the image-based plant disease phenotyping method $(\mathbf{B})$. Scale bars: $1 \mathrm{~cm}$. Data are shown as means $\pm \mathrm{SD}$. Asterisks indicate statistical difference from controls $\left({ }^{*} p<0.05\right)$. (C) Relative NbPR transcript levels in $C b A R 9^{O X} N$. benthamiana plants after C. capsici inoculation, as determined by RT-qPCR. NbActin served as internal reference. Data are shown as means $\pm \mathrm{SD}$. Asterisks indicate statistically significant differences from controls $\left({ }^{*} p<0.05\right.$ and ${ }^{* *} p<0.01$ ). The experiments were repeated at least three times, with similar results.

\subsection{CbAR9-Silenced Pepper Plants Are More Susceptible to C. capsici and C. acutatum Infection}

To further explore the role of CbAR9 in resistance against $C$. capsici, we infected the fruits of $C b A R 9$-silenced chili pepper plants with $C$. capsici for 6 days before scoring the progression of the disease. Accordingly, we silenced $C b A R 9$ in chili pepper fruits by VIGS, which we confirmed by RT-qPCR analysis of silenced chili pepper fruits (Figure 4A). As a result, we found that $C b A R 9$-silenced pepper fruits exhibited much greater susceptibility to $C$. capsici infection (Figure 4B). A quantitative analysis of lesion size caused by C. capsici showed an over 5-fold increase in CbAR9-silenced pepper fruits compared to wild-type fruits (Figure 4C). 
A

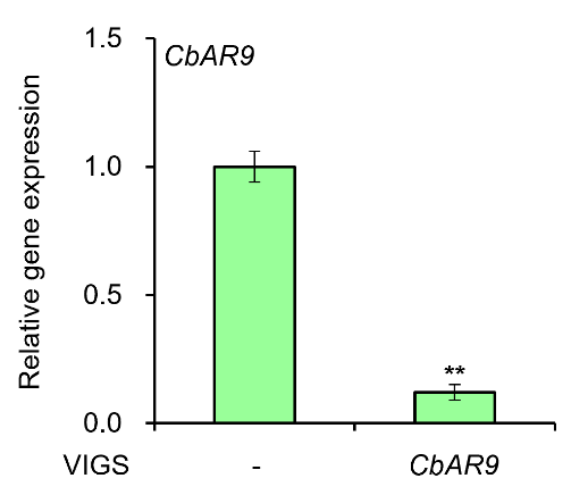

C

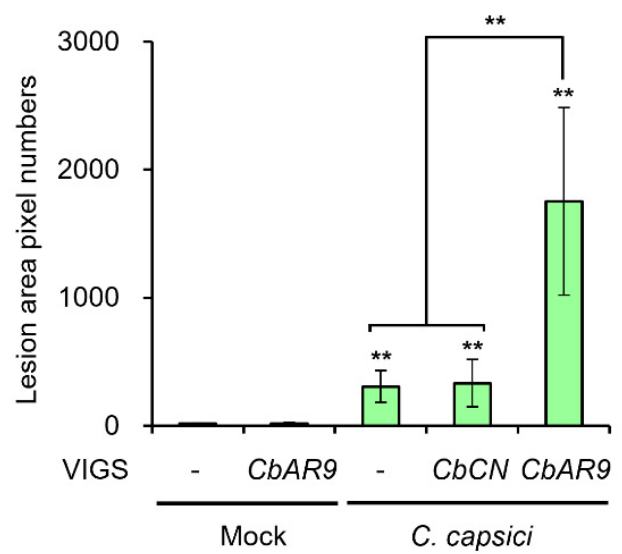

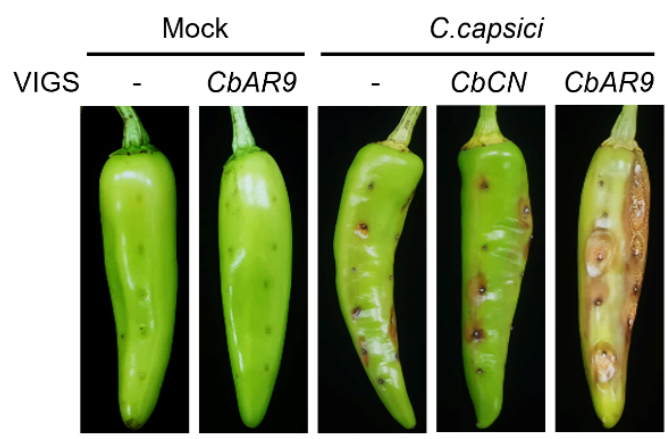

D

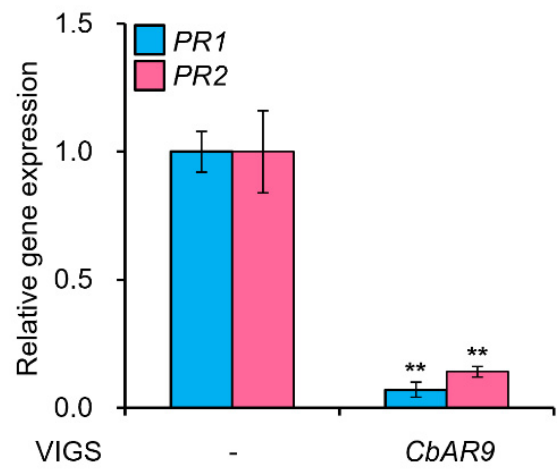

Figure 4. CbAR9-silenced chili pepper fruits are more susceptible to anthracnose after Colletotrichum capsici infection. (A) Relative transcript levels of CbAR9 in control chili pepper fruits and CbAR9silenced fruits for the PBC80 infected with C. capsici. Relative $C b A R 9$ transcript levels were determined by RT-qPCR with Actin as an internal reference. Data are shown as means \pm SD. Asterisks indicate statistically significant differences from controls $(* * p<0.01)$. The experiments were repeated at least three times, with similar results. $(\mathbf{B}, \mathbf{C})$ Anthracnose disease resistance assays with wild-type and VIGS-mediated CbAR9-silenced chili pepper fruits after C. capsici infection. CbAR9-silenced and wild-type chili pepper fruits were inoculated with $C$. capsici. Images were taken 6 days later, and the extent of the disease area was quantified using the image-based plant disease phenotyping method. Data are shown as means $\pm \mathrm{SD}$. Asterisks indicate statistically significant differences from controls (** $p<0.01$ ). (D) Relative PR1 and PR2 transcript levels in CbAR9-silenced and wild-type chili pepper fruits after $C$. capsici infection. Actin served as the internal reference. Data are shown as means $\pm \mathrm{SD}$. Asterisks indicate statistically significant differences from controls $\left({ }^{* *} p<0.01\right)$. The experiments were repeated at least three times, with similar results.

Since overexpression of $C b A R 9$ resulted in higher transcript levels for $P R$ genes after C. capsici inoculation, we determined the effect of $C b A R 9$ silencing on $P R$ gene expression in chili pepper by RT-qPCR on CbAR9-silenced chili pepper fruits inoculated with $C$. capsici. Silencing of $C b A R 9$ reduced $P R 1$ and $P R 2$ transcript levels in response to C. capsici infection (Figure 4D).

\section{Discussion}

Chili pepper is a crop with crucial economic importance worldwide, but it can also be susceptible to anthracnose caused by Colletotrichum. Thus, the identification of gene(s) associated with innate immunity against Colletotrichum species is important for pepper plant breeding. Previous genomic analyses suggested that the NLR protein family is a central regulator of anthracnose resistance in chili pepper [6,41]. However, whether, which, 
and how NLR proteins mediate anthracnose resistance is largely unknown. Since variety PBC80 exhibits BSR to a range of Colletotrichum species such as C. acutatum, C. capsici, and C. gloeosporioides [15], we attempted to identify NLR genes contributing to innate immunity involved in anthracnose resistance in the PBC 80 background (Figure 1A). Accordingly, we describe here $C b A R 9$, which encodes a typical NLR protein, as the likely candidate gene underlying the previously mapped main-effect QTL C $c R 9$ (Figure 1B). Sequence alignment and phylogenic analysis showed that CbAR9 is highly similar to homologous proteins associated with disease resistance in various plant species (Figure 2A,B). This observation suggests that $\mathrm{CbAR} 9$ may be conserved across pathogen-response signaling pathways, which will be useful for plant breeding of other members of the Solanaceae family.

Genes upregulated by a specific pathogen are often expected to associate with innate immunity against the same pathogen [44-46]. Upregulation of CbAR9 transcript levels by $C$. capsici infection prompted us to speculate that $C b A R 9$ plays a role in anthracnose resistance (Figure 2C). To elucidate the function of $\mathrm{CbAR9}$, we also generated and analyzed $N$. benthamiana plants overexpressing $C b A R 9$ (Figure S3A). Surprisingly, despite the absence of a constitutive immunity phenotype (Figure S3B), $C b A R 9 O X$ plants exhibited enhanced disease resistance to C. capsici compared to wild-type plants (Figure 3A,B). This result suggested that CbAR9 is activated by pathogen infection, and it provides evidence that $\mathrm{CbAR} 9$ is involved in ETI signaling pathway triggered by the recognition of pathogen effectors. However, whether CbAR9 acts as sNLR or hNLR must be clarified in future studies.

Since the activation of NLR proteins commonly leads to significant transcriptional reprogramming [47], we monitored the expression of genes related to innate immunity. RT-qPCR analysis showed that $P R$ genes are dramatically induced in $C b A R 9 O X$ plants. As a complementary analysis, we also silenced $C b A R 9$ by VIGS (Figure $4 \mathrm{~A}$ ). $C b A R 9$-silenced chili pepper fruits showed increased susceptibility to C. capsici infection (Figure 4B,C), and $P R 1$ and $P R 2$ transcript levels decreased significantly compared to wild-type plants (Figure 4D). These results showed that CbAR9 is involved in disease response to C. capsici.

Surprisingly, although CbAR9 is $98 \%$ identical to the two homologous proteins of other Capsicum species lacking a resistance to C. capsici (Figure 2A), it dramatically increased the innate immunity against $C$. capsici (Figures 3 and 4). These results imply that the 11 amino acid difference of CbAR9 may be an important site for CbAR9 activation (Figure 2A). A recent study showed that Arabidopsis RRS1/RPS4 NLR protein immune receptor complex is regulated by phosphorylation [48]. Therefore, Ser 216 and Thr 607 on CbAR9 especially need to be tested in future. Investigating and understanding the basis of genetic resistance to relatively understudied pathogen species such as Colletotrichum is important. The effectors from Colletotrichum species and their dedicated NLR receptors in chili pepper remain unknown. Thus, the identification and a deeper understanding of NLR genes from variety $\mathrm{PBC} 80$, which exhibits disease resistance to Colletotrichum species, are important for plant breeding. Our findings will offer new options for pepper plant breeding.

\section{Conclusions}

Here, we identified $C b A R 9$ encoding nucleotide-binding and leucine-rich repeat protein as the causal locus underlying the large effect quantitative trait locus $C c R 9$ from the anthracnose-resistant chili pepper (C. baccatum) variety PBC80. Interestingly, despite the absence of a constitutive immunity phenotype, the anthracnose resistance and transcript levels of $P R$ genes were significantly increased in $C b A R 9$-expressing transgenic $N$. benthamiana lines after $C$. capsici inoculation. Conversely, resistance to anthracnose and transcript levels of $P R$ genes were markedly reduced in $C b A R 9$-silenced chili pepper fruits after $C$. capsici infection. Taken together, we revealed that $C b A R 9$ which is located on CcR9 locus of $\mathrm{PBC} 80$ contributes to innate immunity against $\mathrm{C}$. capsici and regulates gene expression involved in disease response.

The C. baccatum resistant variety PBC 80 contains the noble genes conferring disease resistance and BSR to Colletotrichum species, and they are proposed as a vital biotechnological target for introducing anthracnose resistance. Therefore, identification of $\mathrm{CbAR}$, a positive 
regulator of innate immunity to anthracnose without a constitutive immune phenotype, may offer new possibilities for crop improvement. Moreover, further elucidation of CbAR9 will explain plant defense mechanism against Colletotrichum species and the role of NLR related to its presence in pepper.

\section{Materials and Methods}

\subsection{Plant Material and Growth Conditions}

Seeds of chili pepper (Capsicum baccatum) variety 'PBC 80 ' and Nicotiana benthamiana (N. benthamiana) were surface sterilized in $70 \%$ ethanol for $1 \mathrm{~min}$, followed by $5 \%$ sodium hypochlorite for $3 \mathrm{~min}$, and then washed thoroughly with sterilized distilled water. Clean seeds were then sown on half-strength Murashige and Skoog (MS) medium and placed in a chamber with a programmed photoperiod at $28^{\circ} \mathrm{C}$. Depending on the experiment, aseptic seedlings were kept in a growth chamber or transplanted into pots containing soil in a greenhouse under a programmed $16-\mathrm{h}$ light/8-h dark photoperiod at $28^{\circ} \mathrm{C}$. The humidity was adjusted to $50 \%$.

\subsection{Cloning of CbAR9 and Web-Based Analysis}

The full-length cDNA of CbAR9 (PHT39462) was amplified by PCR with the primers listed in Table S2 from first-strand cDNA prepared from total RNA extracted from variety $\mathrm{PBC} 80$. The $C b A R 9$ cDNA was inserted into the $\mathrm{pENTR}$ entry vector using Gateway BP Clonase II enzyme (Invitrogen, Waltham, MA, USA), and then recombined into destination vectors [49] using Gateway LR Clonase II enzyme (Invitrogen, Waltham, MA, USA) as per the manufacturer's instructions. For subcellular localization and generation of transgenic plants, the CbAR9 cDNA was recombined into the pEarleyGate101 and the pEarleyGate201 vectors, respectively.

The phylogenic tree was generated using the NGPhylogeny (https:/ /ngphylogeny.fr/ workflo-ws/ oneclick/, accessed on 16 May 2020).The CbAR9 amino acid sequence was analyzed for predicted molecular weight and isoelectric point using IPC (http://isoelectric. org/, accessed on 21 July 2020) tools. Conserved domains were predicted with the InterPro software tool (https:/ / www.ebi.ac.uk/interpro/, accessed on 16 May 2020). SmartBLAST (https://blast.ncbi.nlm.nih.gov/smartblast/?LINK_LOC=BlastHomeLink, accessed on 16 May 2020) was used to identify homologs in other plants.

\subsection{Total RNA Extraction and RT-qPCR Analysis}

Total RNA was extracted using TRIzol reagent (Invitrogen, Waltham, MA, USA). First-strand cDNA synthesis was initiated from $2 \mu \mathrm{g}$ of total RNA using Superscript III reverse transcriptase (Invitrogen, Waltham, MA, USA) according to the manufacturer's instructions. RT-qPCR was performed using gene-specific primers (Table S1) on a MyiQ Real-Time PCR System (Bio-Rad, Hercules, CA, USA) using SYBR Green Master Mix (BioRad, Hercules, CA, USA) under the following conditions: 40 cycles of denaturation at $95^{\circ} \mathrm{C}$ for $10 \mathrm{~s}$, annealing at $58^{\circ} \mathrm{C}$ for $15 \mathrm{~s}$, and extension at $72{ }^{\circ} \mathrm{C}$ for $30 \mathrm{~s}$. Relative transcript levels were quantified using the comparative $\mathrm{Ct}$ method, with Actin as an internal reference. All experiments were independently conducted at least three times.

\subsection{N. benthamiana Transformation}

To generate transgenic plants overexpressing CbAR9, the pEarleyGate201-CbAR9 construct was introduced into Agrobacterium strain LBA4404 by electroporation. Positive colonies harboring the construct were selected based on resistance to appropriate antibiotics and grown in YEP medium. Agrobacterium-mediated leaf disk transformation was performed as previously described [50]. Transgenic N. benthamiana lines were selected on MS plates containing antibiotic and propagated to obtain homozygous $\mathrm{T}_{3}$ lines. All transgenic lines were verified by RT-qPCR, and two $\mathrm{T}_{3}$ lines were chosen for detailed analyses. 


\subsection{Anthracnose Disease Resistance Assay}

To test whether CbAR9 modulates disease resistance to anthracnose, we infected $\mathrm{CbAR9OX}$ plants with C. capsici and followed the progression of the disease. Previously reported $C b C N^{O X}$ plant lines conferring disease resistance to $C$. acutatum were used as the control [43]. C. capsici was cultured on potato dextrose agar (PDA) medium for 3 to 7 days with a programmed $12-\mathrm{h} \mathrm{light} / 12$-h dark photoperiod at $28^{\circ} \mathrm{C}$. Conidial suspensions were collected in $3 \mathrm{~mL}$ of sterile distilled water using a scalpel and filtered through two layers of cheesecloth. Their density was adjusted to $1 \times 10^{6}$ conidia $/ \mathrm{mL}$ by adding sterile distilled water and counting with a hemacytometer. Anthracnose disease resistance was assayed using the pinning method with a toothpick for $N$. benthamiana leaves and by microinjection for chili pepper fruits, as previously described [51]. The inoculated plant tissues were incubated at $28^{\circ} \mathrm{C}$ for 6 days. For a more quantitative analysis, the extent of lesion areas was measured using an image-based plant disease phenotyping method [52]. All experiments were performed in triplicate. Consistent results were obtained, and representative data from one replicate are shown.

\subsection{Virus-Induced Gene Silencing (VIGS) of CbAR9 in Chili Pepper}

Transcription levels of $C b A R 9$ were silenced using virus-induced gene silencing (VIGS). Previously reported construct of VIGS for $\mathrm{CbCN}$ silencing was also used as the control [43]. VIGS was performed as previously described [53] with slight modifications. Briefly, the target sequence of $C b A R 9$ for VIGS was amplified by PCR using specific primers (Table S1) and inserted into the pTRV2 vector. The pTRV1 and pTRV2-CbAR9 constructs were transformed into Agrobacterium strain GV3101 by electroporation. Positive colonies harboring the constructs were selected based on resistance to appropriate antibiotics and grown overnight at $28{ }^{\circ} \mathrm{C}$ in YEP medium. The cultures were harvested by quick centrifugation and resuspended in MMA buffer (10 mM MES, $10 \mathrm{mM} \mathrm{MgCl}_{2}$, and $200 \mu \mathrm{M}$ acetosyringone) to a final $\mathrm{OD}_{600}$ of 0.7. Cell suspensions harboring pTRV1 and pTRV2CbAR9 were mixed in a 1:1 $(v / v)$ ratio and infiltrated into chili pepper fruits. The inoculated fruits were placed in the dark at $20^{\circ} \mathrm{C}$ in $50 \%$ relative humidity for $48 \mathrm{~h}$. The plants were then moved to the growth chamber under a 16-h light/8-h dark photoperiod at $28^{\circ} \mathrm{C}$ and incubated for 6 days.

\subsection{Statistical Analysis}

All experiments were independently conducted at least three times, and the data were analyzed by $t$-test using GraphPad Prism 8.0 software, and asterisks denote significant differences $\left(* p<0.05,{ }^{* *} p<0.01\right)$.

Supplementary Materials: The following are available online at https:/ /www.mdpi.com/article/10 $.3390 /$ ijms222212612/s1.

Author Contributions: Conceptualization, S.S., J.H. and S.R.P.; methodology, S.S. and S.R.P.; software, S.S. and J.O.; validation, S.S. and S.R.P.; formal analysis, S.S. and J.O.; investigation, S.S., S.K. and K.S.L.; resources, I.C., J.W.D., J.B.Y. and D.C.; data curation, S.S. and S.R.P.; writing-original draft preparation, S.S.; writing—review and editing, S.S.; visualization, S.S.; supervision, S.R.P.; project administration, S.R.P.; funding acquisition, S.R.P. All authors have read and agreed to the published version of the manuscript.

Funding: This research was funded by Research Program for Agricultural Science and Technology Development (Project No. PJ01323102 and PJ01570601) and the 2021 Post-doctoral Fellowship Program (Project No. PJ01492701) of the National Institute of Agricultural Sciences, Rural Development Administration, Republic of Korea.

Institutional Review Board Statement: Not applicable.

Informed Consent Statement: Not applicable.

Data Availability Statement: The data presented in this study are available in the article or the Supplementary Materials. 
Conflicts of Interest: The authors declare no conflict of interest.

\section{References}

1. Than, P.P.; Prihastuti, H.; Phoulivong, S.; Taylor, P.W.; Hyde, K.D. Chilli anthracnose disease caused by Colletotrichum species. J. Zhejiang Univ. Sci. B 2008, 9, 764-778. [CrossRef]

2. Kim, H.G.; Bae, J.H.; Jastrzebski, Z.; Cherkas, A.; Heo, B.G.; Gorinstein, S.; Ku, Y.G. Binding, Antioxidant and Anti-proliferative Properties of Bioactive Compounds of Sweet Paprika (Capsicum annuum L.). Plant Foods Hum. Nutr. 2016, 71, 129-136. [CrossRef]

3. Surh, Y.J. More than spice: Capsaicin in hot chili peppers makes tumor cells commit suicide. J. Natl. Cancer Inst. 2002, 94, 1263-1265. [CrossRef]

4. Sarkinen, T.; Bohs, L.; Olmstead, R.G.; Knapp, S. A phylogenetic framework for evolutionary study of the nightshades (Solanaceae): A dated 1000-tip tree. BMC Evol. Biol. 2013, 13, 214. [CrossRef]

5. Wu, F.; Tanksley, S.D. Chromosomal evolution in the plant family Solanaceae. BMC Genom. 2010, 11, 182. [CrossRef] [PubMed]

6. Kim, S.; Park, M.; Yeom, S.I.; Kim, Y.M.; Lee, J.M.; Lee, H.A.; Seo, E.; Choi, J.; Cheong, K.; Kim, K.T.; et al. Genome sequence of the hot pepper provides insights into the evolution of pungency in Capsicum species. Nat. Genet. 2014, 46, 270-278. [CrossRef] [PubMed]

7. Barboza, G.E.; Carrizo Garcia, C.; Leiva Gonzalez, S.; Scaldaferro, M.; Reyes, X. Four new species of Capsicum (Solanaceae) from the tropical Andes and an update on the phylogeny of the genus. PLoS ONE 2019, 14, e0209792. [CrossRef]

8. Dias, G.B.; Gomes, V.M.; Moraes, T.M.; Zottich, U.P.; Rabelo, G.R.; Carvalho, A.O.; Moulin, M.; Goncalves, L.S.; Rodrigues, R.; Da Cunha, M. Characterization of Capsicum species using anatomical and molecular data. Genet. Mol. Res. 2013, 12, 6488-6501. [CrossRef]

9. Albrecht, E.; Zhang, D.; Mays, A.D.; Saftner, R.A.; Stommel, J.R. Genetic diversity in Capsicum baccatum is significantly influenced by its ecogeographical distribution. BMC Genet. 2012, 13, 68. [CrossRef] [PubMed]

10. Mahasuk, P.; Taylor, P.W.; Mongkolporn, O. Identification of two new genes conferring resistance to Colletotrichum acutatum in Capsicum baccatum. Phytopathology 2009, 99, 1100-1104. [CrossRef]

11. Bosland, P.W.; Votava, E.J. Peppers: Vegetable and Spice Capsicums, 2nd ed.; CABI: Cambridge, MA, USA, 2012.

12. Schulze-Lefert, P.; Panstruga, R. A molecular evolutionary concept connecting nonhost resistance, pathogen host range, and pathogen speciation. Trends Plant Sci. 2011, 16, 117-125. [CrossRef]

13. Montri, P.; Taylor, P.W.J.; Mongkolporn, O. Pathotypes of Colletotrichum capsici, the Causal Agent of Chili Anthracnose, in Thailand. Plant Dis. 2009, 93, 17-20. [CrossRef]

14. Mongkolporn, O.; Montri, P.; Supakaew, T.; Taylor, P.W.J. Differential Reactions on Mature Green and Ripe Chili Fruit Infected by Three Colletotrichum spp. Plant Dis. 2010, 94, 306-310. [CrossRef]

15. Mahasuk, P.; Chinthaisong, J.; Mongkolporn, O. Differential resistances to anthracnose in Capsicum baccatum as responding to two Colletotrichum pathotypes and inoculation methods. Breed. Sci. 2013, 63, 333-338. [CrossRef]

16. Dangl, J.L.; Horvath, D.M.; Staskawicz, B.J. Pivoting the plant immune system from dissection to deployment. Science 2013, 341, 746-751. [CrossRef] [PubMed]

17. von Moltke, J.; Ayres, J.S.; Kofoed, E.M.; Chavarria-Smith, J.; Vance, R.E. Recognition of bacteria by inflammasomes. Annu. Rev. Immunol. 2013, 31, 73-106. [CrossRef]

18. Jones, J.D.; Vance, R.E.; Dangl, J.L. Intracellular innate immune surveillance devices in plants and animals. Science 2016, 354, aaf6395. [CrossRef] [PubMed]

19. Borrelli, G.M.; Mazzucotelli, E.; Marone, D.; Crosatti, C.; Michelotti, V.; Vale, G.; Mastrangelo, A.M. Regulation and Evolution of NLR Genes: A Close Interconnection for Plant Immunity. Int. J. Mol. Sci. 2018, 19, 1662. [CrossRef]

20. Adachi, H.; Contreras, M.P.; Harant, A.; Wu, C.H.; Derevnina, L.; Sakai, T.; Duggan, C.; Moratto, E.; Bozkurt, T.O.; Maqbool, A.; et al. An N-terminal motif in NLR immune receptors is functionally conserved across distantly related plant species. eLife 2019, 8, e49956. [CrossRef]

21. Monteiro, F.; Nishimura, M.T. Structural, Functional, and Genomic Diversity of Plant NLR Proteins: An Evolved Resource for Rational Engineering of Plant Immunity. Annu. Rev. Phytopathol. 2018, 56, 243-267. [CrossRef] [PubMed]

22. Lolle, S.; Stevens, D.; Coaker, G. Plant NLR-triggered immunity: From receptor activation to downstream signaling. Curr. Opin. Immunol. 2020, 62, 99-105. [CrossRef] [PubMed]

23. Thomma, B.P.; Nurnberger, T.; Joosten, M.H. Of PAMPs and effectors: The blurred PTI-ETI dichotomy. Plant Cell 2011, 23, 4-15. [CrossRef] [PubMed]

24. Roux, F.; Voisin, D.; Badet, T.; Balague, C.; Barlet, X.; Huard-Chauveau, C.; Roby, D.; Raffaele, S. Resistance to phytopathogens e tutti quanti: Placing plant quantitative disease resistance on the map. Mol. Plant Pathol. 2014, 15, 427-432. [CrossRef]

25. Gouveia, B.C.; Calil, I.P.; Machado, J.P.; Santos, A.A.; Fontes, E.P. Immune Receptors and Co-receptors in Antiviral Innate Immunity in Plants. Front. Microbiol. 2016, 7, 2139. [CrossRef]

26. Jones, J.D.; Dangl, J.L. The plant immune system. Nature 2006, 444, 323-329. [CrossRef]

27. Chisholm, S.T.; Coaker, G.; Day, B.; Staskawicz, B.J. Host-microbe interactions: Shaping the evolution of the plant immune response. Cell 2006, 124, 803-814. [CrossRef] [PubMed]

28. Kourelis, J.; van der Hoorn, R.A.L. Defended to the Nines: 25 Years of Resistance Gene Cloning Identifies Nine Mechanisms for R Protein Function. Plant Cell 2018, 30, 285-299. [CrossRef] 
29. Spoel, S.H.; Dong, X. How do plants achieve immunity? Defence without specialized immune cells. Nat. Rev. Immunol. 2012, 12, 89-100. [CrossRef] [PubMed]

30. Wang, J.; Wang, J.; Hu, M.; Wu, S.; Qi, J.; Wang, G.; Han, Z.; Qi, Y.; Gao, N.; Wang, H.W.; et al. Ligand-triggered allosteric ADP release primes a plant NLR complex. Science 2019, 364, eaav5868. [CrossRef]

31. Hammond-Kosack, K.E.; Jones, J.D. Resistance gene-dependent plant defense responses. Plant Cell 1996, 8, $1773-1791$.

32. Durrant, W.E.; Dong, X. Systemic acquired resistance. Annu Rev. Phytopathol. 2004, 42, 185-209. [CrossRef] [PubMed]

33. Jubic, L.M.; Saile, S.; Furzer, O.J.; El Kasmi, F.; Dangl, J.L. Help wanted: Helper NLRs and plant immune responses. Curr. Opin. Plant Biol. 2019, 50, 82-94. [CrossRef]

34. Kourelis, J.; Sakai, T.; Adachi, H.; Kamoun, S. RefPlantNLR is a comprehensive collection of experimentally validated plant disease resistance proteins from the NLR family. PLoS Biol. 2021, 19, e3001124. [CrossRef]

35. Dodds, P.N.; Rathjen, J.P. Plant immunity: Towards an integrated view of plant-pathogen interactions. Nat. Rev. Genet. 2010, 11, 539-548. [CrossRef]

36. Varden, F.A.; Saitoh, H.; Yoshino, K.; Franceschetti, M.; Kamoun, S.; Terauchi, R.; Banfield, M.J. Cross-reactivity of a rice NLR immune receptor to distinct effectors from the rice blast pathogen Magnaporthe oryzae provides partial disease resistance. J. Biol. Chem. 2019, 294, 13006-13016. [CrossRef] [PubMed]

37. Cesari, S.; Bernoux, M.; Moncuquet, P.; Kroj, T.; Dodds, P.N. A novel conserved mechanism for plant NLR protein pairs: The "integrated decoy" hypothesis. Front. Plant Sci. 2014, 5, 606. [CrossRef]

38. Bonardi, V.; Tang, S.; Stallmann, A.; Roberts, M.; Cherkis, K.; Dangl, J.L. Expanded functions for a family of plant intracellular immune receptors beyond specific recognition of pathogen effectors. Proc. Natl. Acad. Sci. USA 2011, 108, 16463-16468. [CrossRef]

39. Wang, J.; Chai, J. Structural Insights into the Plant Immune Receptors PRRs and NLRs. Plant Physiol. 2020, 182, 1566-1581. [CrossRef] [PubMed]

40. Ridzuan, R.; Rafii, M.Y.; Ismail, S.I.; Mohammad Yusoff, M.; Miah, G.; Usman, M. Breeding for Anthracnose Disease Resistance in Chili: Progress and Prospects. Int. J. Mol. Sci. 2018, 19, 3122. [CrossRef]

41. Kim, S.; Park, J.; Yeom, S.I.; Kim, Y.M.; Seo, E.; Kim, K.T.; Kim, M.S.; Lee, J.M.; Cheong, K.; Shin, H.S.; et al. New reference genome sequences of hot pepper reveal the massive evolution of plant disease-resistance genes by retroduplication. Genome Biol. 2017, 18, 210. [CrossRef] [PubMed]

42. Lee, J.; Hong, J.-H.; Do, J.W.; Yoon, J.B. Identification of QTLs for resistance to anthracnose to two Colletotrichum species in pepper. J. Crop. Sci. Biotechnol. 2010, 13, 227-233. [CrossRef]

43. Son, S.; Kim, S.; Lee, K.S.; Oh, J.; Choi, I.; Do, J.W.; Yoon, J.B.; Han, J.; Park, S.R. The Capsicum baccatum-Specific Truncated NLR Protein $\mathrm{CbCN}$ Enhances the Innate Immunity against Colletotrichum acutatum. Int. J. Mol. Sci. 2021, 22, 7672. [CrossRef]

44. Lai, Y.; Eulgem, T. Transcript-level expression control. of plant NLR genes. Mol. Plant Pathol. 2018, 19, 1267-1281. [CrossRef]

45. Eulgem, T.; Weigman, V.J.; Chang, H.S.; McDowell, J.M.; Holub, E.B.; Glazebrook, J.; Zhu, T.; Dangl, J.L. Gene expression signatures from three genetically separable resistance gene signaling pathways for downy mildew resistance. Plant Physiol. 2004, 135, 1129-1144. [CrossRef] [PubMed]

46. Rosli, H.G.; Zheng, Y.; Pombo, M.A.; Zhong, S.; Bombarely, A.; Fei, Z.; Collmer, A.; Martin, G.B. Transcriptomics-based screen for genes induced by flagellin and repressed by pathogen effectors identifies a cell wall-associated kinase involved in plant immunity. Genome Biol. 2013, 14, R139. [CrossRef]

47. Nguyen, Q.M.; Iswanto, A.B.B.; Son, G.H.; Kim, S.H. Recent Advances in Effector-Triggered Immunity in Plants: New Pieces in the Puzzle Create a Different Paradigm. Int. J. Mol. Sci. 2021, 22, 4709. [CrossRef]

48. Guo, H.; Ahn, H.K.; Sklenar, J.; Huang, J.; Ma, Y.; Ding, P.; Menke, F.L.H.; Jones, J.D.G. Phosphorylation-Regulated Activation of the Arabidopsis RRS1-R/RPS4 Immune Receptor Complex Reveals Two Distinct Effector Recognition Mechanisms. Cell Host Microbe 2020, 27, 769-781.e6. [CrossRef] [PubMed]

49. Earley, K.W.; Haag, J.R.; Pontes, O.; Opper, K.; Juehne, T.; Song, K.; Pikaard, C.S. Gateway-compatible vectors for plant functional genomics and proteomics. Plant J. 2006, 45, 616-629. [CrossRef]

50. Sohn, S.; Choi, M.S.; Kim, K.; Lomonossoff, G. The epigenetic phenotypes in transgenic Nicotiana benthamiana for CaMV 35S-GFP are mediated by spontaneous transgene silencing. Plant Biotechnol. Rep. 2011, 5, 273-281. [CrossRef]

51. Yoon, J.B.; Park, H.G. Screening method for resistance to pepper fruit anthracnose: Pathogen sporulation, inoculation methods related to inoculum concentrations and post-inoculation environment. J. Kor. Soc. Hort. Sci. 2001, 42, 389-393.

52. Mutka, A.M.; Fentress, S.J.; Sher, J.W.; Berry, J.C.; Pretz, C.; Nusinow, D.A.; Bart, R. Quantitative, Image-Based Phenotyping Methods Provide Insight into Spatial and Temporal Dimensions of Plant Disease. Plant Physiol. 2016, 172, 650-660. [CrossRef] [PubMed]

53. Tian, S.L.; Li, L.; Chai, W.G.; Shah, S.N.; Gong, Z.H. Effects of silencing key genes in the capsanthin biosynthetic pathway on fruit color of detached pepper fruits. BMC Plant Biol. 2014, 14, 314. [CrossRef] [PubMed] 